\title{
Awareness of Emergency Nursing Staff about Emergency Operations Plan in a Tertiary Care Hospital in Riyadh, Saudi Arabia
}

\section{Faisal Alasmari ${ }^{1 *}$, Abdulaziz Albuhayri ${ }^{1}$, Jean Bail ${ }^{2}$, Steven Parrillo ${ }^{2}$, Maher Alsakkak $^{1}$ and Mostafa Kofi ${ }^{1}$}

${ }^{1}$ Family and Community Medicine Department Prince Sultan Military Medical City, PSMMC, Riyadh, Saudi Arabia

${ }^{2}$ Thomas Jefferson University, Philadelphia, USA

*Corresponding Author: Faisal Alasmari, Family and Community Medicine Department Prince Sultan

Military Medical City, PSMMC, Riyadh, Saudi Arabia.dmmjef@gmail.com.
Received: November 18, 2021

Published: January 01, 2022

(C) All rights are reserved by Faisal Alasmari., et al.

\begin{abstract}
This paper offers a project to assess nurses' disaster readiness in the Prince Sultan Military Medical City emergency department. The study aims to determine the level of awareness of the concept of the EOP and preparedness among emergency department nurses for a large-scale disaster. With the hospital implementing an emergency operation plan, it is unclear whether emergency department nurses are conversant with it. An extensive literature review discussing incident command systems, regulations and standards, disasters in Saudi Arabia, and preparedness has been conducted in this paper. Data was collected using survey questionnaires developed by the Qualtrics platform and distributed to a sample of nurses in the department. The project outcomes will help outline areas that need improvement. Findings show that ED nurses have a lack of knowledge about disaster preparation. They need educational, practical, and awareness programs to cultivate their confront disasters' competencies. Some recommendations have been presented to the Major Disaster Response Unit (MDRU) to perform and provide additional educational and training approaches for the ED nurses about the EOP and disaster response.
\end{abstract}

Keywords: Nursing; Saudi Arabia; Disaster

\section{Introduction}

Disaster preparedness and response in the emergency department (ED) depend on nurses' competence and familiarity with the emergency operation plan. Many factors place those ER nurses in a position to deal and share their responsibility, competencies, and awareness of the emergency operation plan (EOP) with other ER professionals to manage any crisis. Standard practice requires that every hospital has an emergency operation plan (EOP), which defines how the hospital will respond to any hazard and recover. An EOP is important because it prepares the hospital to respond to different hazards, having varied durations, and scale. The EOP is developed using an all-hazards approach to ensure that the hospital is prepared for emergencies of different scales. More importantly, hospital staff needs to know of the existence of such a plan and comprehend its contents. When a disaster occurs, staff need to be prepared to implement the EOP. Although the preparation and maintenance of an EOP are essential, implementing this plan largely depends on the healthcare staff's comprehension of its details.

\section{Literature Review}

There is overwhelming evidence supporting the need to plan for events, hazards, and threats that may hinder healthcare access in a 
community. A healthcare organization remains a crucial aspect of the community and its ability to deliver care especially during a disaster or hazard is a measure of its utility to the community. Prince Sultan Military Medical City (PSMMC), located in Riyadh, is one of the most advanced health centers in Saudi Arabia and the Middle Eastern Region. Like other health centers, this hospital has developed and maintained an EOP in readiness for any emergencies that may occur in the community or internally in the facility. However, it is not clear whether ED nurses are conversant with the principles and processes outlined in the EOP for the hospital. Emergency nurses are instrumental in the response to a disaster since they are frontline staff in such instances. The purpose of this project is to determine how conversant ED nurses at Prince Sultan Military Medical City are with the hospital's emergency operations plan and how prepared they are to apply the EOP in case of a disaster.

The role of a hospital during and after a disaster is integral and critical for effective response and recovery. Following an incident that results in loss of infrastructure and surge of patients, a multifunctional and multijurisdictional response is launched with the local health systems in the midst of these responses. Without the proper infrastructure and expertise, healthcare centers and the workers in them can easily become overwhelmed when providing care [1]. Therefore, staff in any hospital should prepare for any disaster through training to develop expertise on how to handle such an incident. Similarly, in PSMMC, the hospital and the staff should be well-prepared for any disaster that may occur. This project will ascertain and determine the level of preparedness in the medical center and develop an intervention to address gaps in knowledge and preparedness.

The project focuses specifically on ED nurses who are central to any emergency and disaster response. The role of the nurse in a healthcare system is to provide care that enhances the patient's healing and comfort. Nurses are thus instrumental in the preservation of life following a disaster. When a community experiences a disaster, nurses are on the front lines helping to rescue and attend to those who are affected [1]. Nurses need a broad scope of knowledge to be effective in emergency response and management and the complexity of disasters requires that nurses are conversant with disaster response procedures. This project seeks to determine whether ED nurses at PSMMC understand the processes and procedures for disaster response and also assess their confidence on the same. This project is needed to provide certainty to the community that the local health system is well-prepared in case of a disaster.

While narrowing the scope to Riyadh where PSMMC is located, the hospital is a crucial asset for the community and nurses in the medical city are paramount in any disaster that may strike the community. PSMMC is one of the largest and most advanced hospitals in Saudi Arabia. In the event of a disaster, it would be one of the core response centers for rescue and treatment of casualties. Its importance to the public cannot be overemphasized. Additionally, preliminary research in two government hospitals in Riyadh shows that majority of ED nurses did not have

confidence in their disaster response knowledge and abilities [2]. This research shows that there is need for more assessments and training for ED nurses in readiness for any disaster. Current evidence shows the importance of ED nurses in disaster response and also highlights the unpreparedness of nurses in some of the hospitals in Riyadh, Saudi Arabia.

\section{Disasters}

The past few decades have seen a lot of disasters claiming millions of lives and billions in economic losses. According to $\mathrm{Al}$ Bassam, A., et al. 2014 [3] reported that disasters have increased because of the inhabitation of areas prone to natural hazards such as flood plains, flanks of volcanoes, and low-lying subsiding areas in coastal regions. The most common natural disasters worldwide include tsunamis, earthquakes, floods, and hurricanes. The Kingdom of Saudi Arabia [KSA] is also prone to disasters and in the last three decades has lost lives and property due to the occurrence of such disasters [3]. Disasters remain a critical threat to community and national development and people's livelihood.

It is necessary to define the term 'disaster' before delving into the history of disasters and their connection to PSMMC ED. According to the World Health Organization [4], a disaster is "a situation or event, which overwhelms local capacity, necessitating a request to the national or international level for external assistance." Other agencies may define disaster differently depending on the purpose of the definition and scope of operations. In summary, a disaster can be defined as an event that disrupts the normal functioning of a community and causes substantial loss of property and life, overwhelming the community's ability to use its own resources in re- 
sponse and recovery [5]. This definition focuses first on the effects of the event and the scope of the same. The effects are communitywide and hence the event affects a significant portion of the community. Moreover, the scope is such that it overwhelms the community's capacity to respond due to loss of infrastructure and life.

Additionally, emergency management agencies and agents view disasters as the ultimate events that a health system should respond to [6]. The ED responds to emergencies of different intensity and scope including events such as road accidents. However, when an event is classified as a disaster, the ED is often fully engaged in the response such that it dedicates all its infrastructure to respond to the event [5]. Natural disasters include floods, earthquake, and hurricanes among others. Manmade disasters may include terror attacks, wars, human stampede, and explosions. The distinction between the two is that while natural disasters occur with no direct human involvement, manmade disasters are often a result of direct human engagement [6]. Regardless of the source of a disaster, emergency services are often critical to saving lives during the response phase. Therefore, they remain critical to the city of Riyadh.

The Kingdom of Saudi Arabia [KSA] has experienced a lot of disasters which necessitate the preparedness of ED's and health care systems. The most common disasters affecting KSA are heat waves in gathering events such as Hajj, sand storms, earthquakes, ballistics attacks, and flash floods. The Northwestern region of KSA has largely been affected by earthquakes and volcanic hazards while the central and western regions are known for flash floods [3]. Some of the notable natural disasters in the kingdom include the earthquakes in the Gulf of Aqaba in 1983, 1990, 1993, 1995, and 2004 [3]. Al-Bassam., et al. 2014 [3] recalled the 2009 Jeddah floods as a significant disaster that affected KSA. One of the most recent natural disasters is the COVID-19 pandemic which has so far caused over 6,200 deaths in the kingdom [7]. These disasters have highlighted the importance of emergency operations and expertise in the kingdom of Saudi Arabia the need for rigorous training of healthcare personnel on preparedness and response to disasters.

\section{Disaster preparedness}

A crucial concept in emergency services is disaster preparedness which determines how well a unit or agency is prepared for different disasters. The primary goal of disaster preparedness is to prepare a response that will minimize damages and enhance the recovery process [8]. Healthcare agencies count damages of disaster in terms of impact on human life and hence disaster preparedness is the process of preparing a response that would minimize the impact of disaster on human life including injury and deaths [8]. Nurses have expertise in clinical work, interdisciplinary collaboration, and leadership and hence they are pivotal for the disaster preparedness phase [8]. It is critical to note that the entire process of preparedness, mitigation, response, and recovery involves interdisciplinary and interprofessional collaboration among different experts and agencies. Therefore, nurses need the skills for interprofessional collaboration to effectively prepare for any disaster.

The first step of disaster preparedness is to prepare an emergency management plan. In the scope of health and medical services, this management plan is the emergency operation plan [EOP] which is maintained in every hospital. Aspects that should be included in the EOP include the command and control plan, roles and responsibilities of parties to be involved in disaster, a communication system, specific response plans to the high priority and also unexpected disasters [9]. The EOP is comprehensive in that a reader conversant with its contents and having been trained in their role should competently respond to a disaster. Although the EOP may be comprehensive, the main issue arises in the training and familiarity of the stakeholders with the EOP processes and knowledge included in the plan. Completion of the EOP includes the training of relevant stakeholders in the response plan [9]. Therefore, all organizations with an EOP are required to train their staff and other stakeholders in their roles and responsibilities to maintain a state of preparedness.

Challenges and resources for nurses participating in a hurricane sandy hospital evacuation

Behind the success of every disaster response plan is an effective communication plan during preparation and response process [10]. studied the common challenges faced during response to Hurricane Sandy and found that communication was a major problem.

Due to the effects of the hurricane, the Internet was down and other means of communication were also down. Such occurrences limited nurses and other responders to face to face communication with no consistent communication means [10]. The impact of inadequate communication modalities is emphasized by Azmani., et al. 2017 [11] who highlight the slowdown in efficiency as well as 
distress for the people involved in the response. Communication, therefore, comes across as a central concept in preparedness and the response plan.

In addition to the failure of communication equipment, staff training for effective communication and care coordination is another major challenge for disaster preparedness. In the Hurricane Sandy case study, the authors determined that although staff had been trained on evacuation, they had little hands-on experience in communications during a disaster [10]. This lack of preparedness leads to the necessity for improvisation during the response process. According to Roud, E. 2021 [12], the unpredictable nature of disaster requires collective improvisation in order for organizations to respond effectively. In the Hurricane Sandy case study, nurses improvised by using their cell phones to communicate with each other and physically moving from one unit to the other to communicate face to face [10]. While this improvisation is excellent in ensuring the best outcome out of a lousy disaster situation, it leads to the need for a practical review of the communication tools and communication training programs that help acquire the ideal disaster response and management for ED nurses.

\section{State of preparedness in KSA}

The Kingdom of Saudi Arabia has taken significant steps to enhance disaster risk management as a collaborative effort among agencies and within institutions. The Civil Defense Ministry of Interior oversees national planning and coordination of response and the Presidency of Meteorology and Environment is in charge of disaster mitigation [13]. The kingdom has also taken significant steps to collaborate with governments and agencies in the region to ensure coordinated responses to both natural and manmade disasters. The Saudi Red Crescent Authority is in charge of medical emergency services in many areas of the kingdom and hence coordinates the medical response to any disaster that may occur in the nation [13]. The Saudi Red Crescent collaborates with the Ministry of Health and Saudi Humanitarian Emergency Aid and Response Team [Saudi HEART] for preparedness and management of response efforts [13]. On a macro-level, the kingdom presents readiness for disaster and has made efforts to mitigate hazards. Although the kingdom has a high level of preparedness on the national level, current evidence shows that there is a gap in the preparedness of ED nurses. Alzarani, F. 2017 [2] stated that majority of emergency nurses in two government hospitals in Riyadh lacked the confidence for disaster response despite having undergone training. Moreover, a study in Mecca showed that more than half of emergency nurses in that city had not fully read the EOP and were not aware of the larger disaster preparedness and response plans [2]. Another study of the southern part of Saudi Arabia showed that although most emergency nurses showed knowledge of the theoretical aspects of disaster management, majority showed weakness in the practical dimensions of disaster response and management [14]. This evidence shows that a significant number of emergency nurses in Saudi Arabia either lack the knowledge and awareness of disaster preparedness or are not confident of their practical abilities to effectively respond to a disaster. Based on the review of current literature, it is apparent that disasters are common in the KSA and there is a need for preparedness. It has also been shown that healthcare organizations and their staff, especially nurses, are critical to the successful response to disasters. Having a wellmaintained EOP is not enough for a healthcare organization. It is necessary for staff and all stakeholders to be aware of the EOP and be trained in their capacity for effective disaster response. The literature also shows that many nurses in the kingdom, and Riyadh in particular, may lack the practical skills to implement the processes and principles outlined in their organizations' EOP. This review of the literature thus necessitates the current study in PSMMC to determine whether ED nurses are familiar with the EOP and competent to respond to a disaster. The current study focuses on PSMMC to determine any gaps in knowledge and competence and close those gaps through training to enhance ED nurses' preparedness for disaster.

\section{Models for planning and preparedness}

Planning for mass casualty incidents [MCI] has been identified as a major requirement for disaster preparedness in healthcare organizations. Many healthcare organizations are faced with the challenge of assigning relevant resources to all requirements during a disaster [15]. Nevertheless, the mixed integer programming [MIP] approach has been extensively used in MCI situations. According to Yip, S. 2019 [16], the method is a supply chain network programming model that is used to determine the relevant resources for each of the requirements. The aim of MIP is to allocate resources effectively to meet all the needs during the mass casualty incident. The objectives are to reduce response time and patient flow time in order to provide prompt and adequate care to those in need [16]. The advantage of MIP is in the ability to react 
to uncertainties during disaster. The planning method is limited to management who are involved in the allocation of resources and conducting the entire operation as opposed to frontline workers such as nurses on the hospital floor [15]. Other than the MIP which requires technological expertise, hospital incident command systems [HICS] have also been extensively used and also proposed and implemented under the Federal Emergency Management Agency [FEMA] protocols [17]. HICS basically involves a centralized command system whereby a single authority [individual] provides the relevant orders under consultation with the bodies and stakeholders involved in the process [18]. HICS may be implemented in different situations and in public disasters, the local authority determines the structure of the HICS. HICS uses the same concepts of ICS but implements those concepts in a hospital and healthcare facility with more medical resources need to manage the crisis. HICS is a methodology for using incident command system [ICS] in a hospital/healthcare environment [19]. Likewise, HICS facilitates hospitals and healthcare institutions to activate and use their emergency management plans. In hospitals, a HICS is established by the emergency operations center and in some incidences, a joint operations center is set up [18]. In a hospital setting, readiness to collaborate among departments as well as with other disaster response bodies such as the fire department is key since it enhances success [17]. Using a HICS provides the advantage of coordination of responses with a shared objective and plan of action to optimize resources and achieve the best outcomes for the population involved.

Challenges and opportunities using incident command systems

For the nurse to be ready and prepared to respond to disaster, she/he must show competencies in disaster preparedness and the HICS [Hospital Incident Command System]. According to Al Thobaity., et al. 2017 [20], one of the core competence areas is knowledge of the HICS. Knowledge of the command system determines the nurse's ability to respond effectively to disaster and collaborate with colleagues. Similarly, being aware and well informed of the HICS increases the nurse's ability to participate in planning and communicating the disaster response plan [20]. Communication and knowledge of the HICS are essential competencies for disaster nursing and adherence to the disaster response and recovery plan.

Moreover, Sultan., et al. 2020 [14] reviewed nurses' familiarity with the HICS of their hospitals in Saudi Arabia and outlined as- pects that were most familiar and needed more learning. The study determined that, in general, the nurses were aware of their roles and steps to be taken during a large-scale disaster. However, most nurses were unclear about which functional group of the HICS they would be assigned during disaster response [14]. They were also unsure of the strategic rationale used to develop the incident command system [14]. Therefore, although many nurses may be aware of the steps to take as defined in the HICS, most do not understand the rationale behind these steps and relevant planning.

Additionally, it is necessary to integrate the HICS into disaster planning and response as it is an integral part of the EOP and response plan. According to Farcas., et al. 2020 [17], the integration of HICS into FEMA and federal guidelines is based on the concept of a unified approach in disaster response so that there is a suitable set of objectives. The importance of the HICS to nurses is to organize and promote a common set of goals. Nevertheless, Farcas., et al. 2020 [17] warn that the HICS should enhance the response activities rather than restrict them. Therefore, nurse knowledge of the HICS is associated with a better understanding of the relevant response activities.

\section{Disaster preparedness standards}

Standards for disaster preparedness are advanced by regulatory bodies to ensure that hospitals and other entities are ready to handle a disaster when it occurs. As a rule of thumb, all healthcare organizations are required to have an EOP in place and train their staff on response to disaster [21]. The extent of the EOP and training requirements may differ from one hospital to another and also depending on the type of hospital which the EOP is developed for. Regulatory bodies issuing standards and regulation requirements include the Kingdom of Saudi Ministry of Health [MOH] and the Presidency of Meteorology and Environment which are responsible for public health and disaster risk reduction respectively [8]. Furthermore, the Saudi Central Board for Accreditation of Healthcare Accreditation [CBAHI] has imposed some essential requirements for patient and staff safety to get the annual accreditation as a part of the emergency management standard. These requirements, coded as IPC4, FMS9, FMS21, FMS22, FMS23, and FMS32, are standard requirements for any fire, infection outbreak, and evacuation processes. The Essential National Requirements for Patient Safety is a list of 20 national standards for hospitals. They are deemed to be basic conditions that must be fully observed to ensure pa- 
tient safety and protection against healthcare related errors [22]. Besides, In other nations such as the U.S, the federal government issues general directions and state and local authorities are in charge of preparedness and response to disaster. Disaster preparedness standards are a collaborative effort between agencies and often developed with the different stakeholder roles in consideration.

Moreover, despite having regulatory authorities and bodies in charge of preparedness and response, Saudi Arabia lacks national standards for disaster management [8]. Therefore, most of the standards used in the country are based on international bodies and consensus on what should be captured in an EOP. For instance, a study by Al Thobaity., et al. 2019 [23] showed that the five key factors of an EOP in Saudi Arabia hospitals include communication, safety and security, decontamination, survivor support, and surge capacity. These aspects of the EOP can be used in education, planning, and response activities and have been highlighted as the most crucial in Saudi Arabia hospitals [23].

Despite the absence of national standards, most hospitals develop and rely on international standards such as the Health Standards Organization [HSO]. Hospital accreditation with different bodies often requires compliance with set standards. For instance, Bajow and Alkhalil, 2014 [24] identify that many hospitals have only adhered to Joint Commission International on Accreditation of Healthcare Organizations standards in written form for accreditation purposes [25]. Moreover, the Joint Commission International mandates that the healthcare organization must develop a facility management and safety structure for effective EOP implementation in disaster response. The lack of national standards has been identified as leading to poor implementation of EOP with low utility in an actual disaster [24]. The training level of ED nurses in the KSA is still lacking. According to Sultan., et al. 2020 [14], 28\% of nurses in the KSA have inadequate knowledge and training on disasters and major incidents response. This review of the literature shows that nurses in hospitals in Saudi Arabia might have low disaster preparedness due to the current regulation and standards conditions hence the need to improve their competence in using the EOP.

\section{Methods}

Study design

To accomplish the objectives of this research, a mixed qualitative and quantitative was adopted to gauge the percentages of nurses who indicate preparedness in the different aspects and knowledge of EOP and practical aspects in response to the disaster and themes indicating the level of readiness. Researchers have used this design in past studies, especially when seeking to determine the causal effects of different constructs on a studied phenomenon [26]. This allows for evaluation of the "what" component in research rather than "how" and "why." In this study, the researcher examines the readiness levels of the Emergency Department nurses in handling disaster management. Therefore, the study will highlight the underlying characteristics of nurses' awareness and preparedness in emergency disaster management. Further, there were qualitative aspects of the study, and so were the quantitative aspects.

\section{Measures}

Some of the measures that the study adopted to guide the data collection process varied depending on the thematic substance of the questions. The first theme was to determine the level of preparedness and awareness of handling emergencies in their capacities as nurses, the respondents' ability to describe EOP, their confidence in Activation EOP, willingness to learn, and finally, confidence in filling EOP forms. The second theme's measures included evaluating the opportunities for activating disaster codes at EOC, ED nurses' ability to participate and learn from TTX exercises, and confidence in evacuating victims as per the EOP guidelines. Finally, the researcher investigated the resources for risk management. The measures developed for this include the training status of the nurses by MDRU and the respondents' awareness of the tools.

\section{Data collection instruments}

The primary data collection tool used in this study was the questionnaire instrument using Qualtrics platform. The instrument was deemed the most appropriate because of its flexibility in accommodating the collecting of qualitative and quantitative data. Therefore, the questionnaire was supplied to the respondents by Qualtrics platform secured link and distributed using WhatsApp and PSMMC email application. After completing the questionnaires, including multiple-choice and short answers, they were sent back to the researcher to code and prepare the combined dataset. One hundred sixty-one completed questionnaires were received from the respondents at the end of the data collection period, precisely on April 22, 2021. Collectively, these measures provide information on the nurses' confidence and awareness of the operationalization of Emergency Operation Plans (EOP). 


\section{Creating a survey and validating}

A survey was developed on the Qualtrics platform. The contents of the survey revolved around the nurses' awareness of the EOP and its content. Nurses were also be asked about training on the EOP, their level of knowledge on disaster response, and confidence in their practical abilities to effectively respond to a disaster. The survey was validated through a pilot study with four nurses who highlighted the utility of the survey questions and relevant changes needed. The study participants sent the updated survey via email or trusted social media platforms such as WhatsApp and email platforms.

\section{Sample size determination}

The target population for this study included all ED charge nurses and supervisors at PSMMC. This population was targeted due to their pivotal role in disaster response since they are considered among the first responder pool. Charge nurses carry out clinical work and also have supervisory duties. Therefore, in addition to being active in the frontline in times of disaster, they also have a leadership role of coordinating with ED nurses and professionals. The ED has exactly 554 nurses ( 5 Head nurses, 18 Head nurses, 156 Staff nurses One, 312 Staff nurses Two, 63 Staff nurses Three), and the sample for this study will be 161 nurses $(n=161)$, inclusive of at least 25 charge nurses. The reason for selecting both bedside and in-charge nurses is that bedside nurses and in-charge nurses may have different readiness levels. A convenience sampling procedure was adopted to identify such personnel as many other medical practitioners are housed within the organization. Additionally, the hospital environment has numerous activities that limited the time for the respondents to provide information. Therefore, only available respondents were included.

\section{Data analysis}

Data analysis was conducted using SPPS Version 23 and Microsoft Excel. The researcher presented the study findings using frequencies presented in Tables, 3D pie charts, and bar charts. The qualitative data was analyzed using excel, and P-value statistical Hypothesis test was used, where common themes were grouped and deductions made based on the frequency of their appearances.

\section{IRB process}

The researcher prepared a proposal and sent it to the research ethical committee on February $17^{\text {th }}, 2021$. The researcher assessed the population through requests sent through the hospital for them to participate, and nurses who provide consent had filled the consent forms. These documents have been presented to the committee, and approval has been obtained from the ethical committee (see Appendix B).

\section{Results and Interpretation}

Theme 1: Demographic analysis

User languages

The primary languages assessed in the study were English and Arabic language. Ninety nine percent $(n=161)$ of the respondents indicated that they used English as their primary language of communication while in the line of duty. A meager $1 \%(n=2)$ used Arabic as their primary mode of communication.

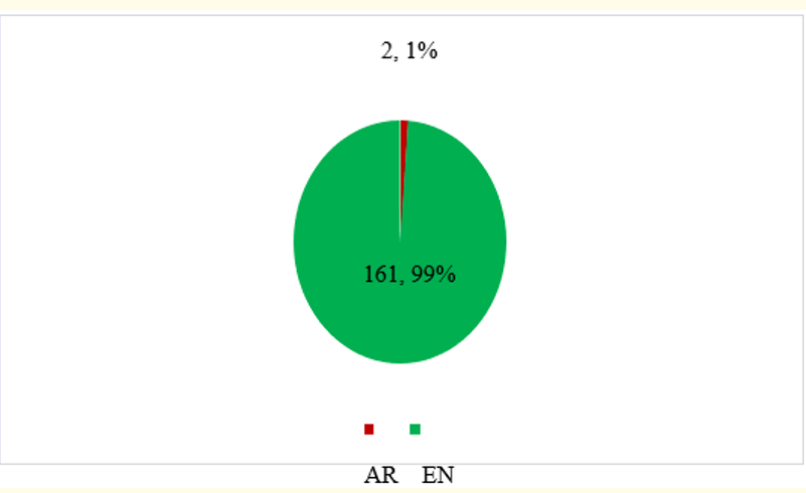

Figure 1: User languages.

\section{Gender distribution}

In terms of gender distribution, there were more female $(88 \%$, $\mathrm{n}=141)$ than male compared to male nurses $(12 \%, \mathrm{n}=19)$. Based on the target population description, all ED charge nurses and supervisors at PSMMC were evaluated. This means that more female nurses participated on the survey at ED than male nurses.

\section{Work experience}

The respondents were queried on the duration that they had worked for their organization. Forty-three percent $(n=69)$ reported that they had served within the organization for more than 4 years. The second-largest number $(29 \%, n=47)$ had served at PSMMC between 1 and 2 years, and finally, 28\% $(n=44)$ reported working at the institution for a period of 3 and 4 years. 


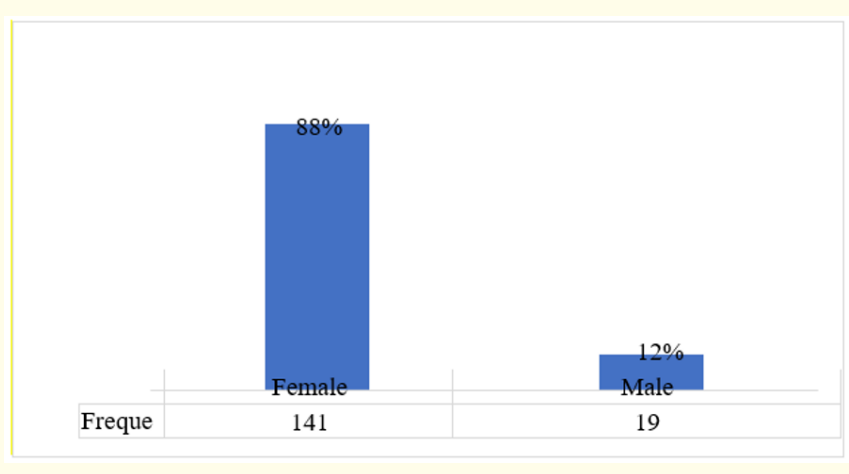

Figure 2: Gender distribution.

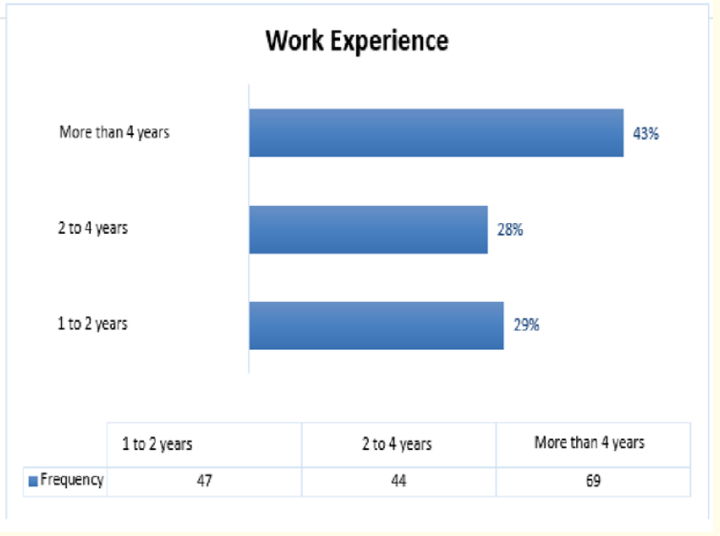

Figure 3: Work Experience.

\section{ED nurse cadres}

The distribution of nurses in terms of their positions within the organization revealed that the most significant cadre of nurses were Staff nurse Two (SN2) nurses $(60 \%, \mathrm{n}=96)$. The Staff nurses One (SN1) came second, with a total of 47 (29\%) nurses reporting to belong to this cadre.

Theme 2: Level of confidence of awareness and preparedness

The level of awareness and preparedness for disaster management among the ED nurses was significantly lower than their lack of confidence. Approximately 44\% ( $n=66)$ of the respondents indicated that they were completely confident about their preparedness. Seventy fife percent (75\%) of the head nurses who participated in the survey were completely confident about their

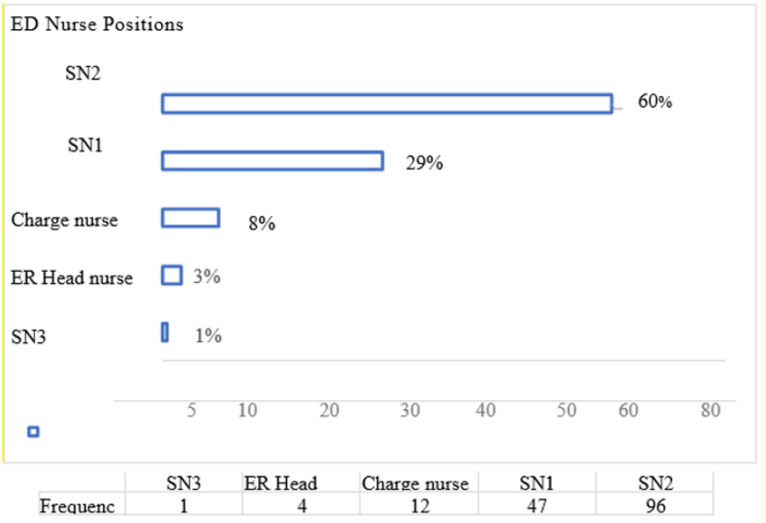

Figure 4: Nurses' Cadres.

preparedness $(n=3)$. On the other hand, more than $55 \%$ of the charge nurse were very confident on their preparedness in case of any crisis $(n=7)$. The preparedness was evaluated based on the participants' answers showing the roles of individual nurses in the emergency department.

The respondent's awareness levels on EOP were uneven, but a significant majority expressed a lack of confidence in conveying their understanding. Thirty-nine respondents (30\%) are utterly confident of their knowledge about the EOP. However, the majority are not entirely confident about activating the EOP $(69 \%, n=90)$.

\begin{tabular}{|c|c|c|c|}
\hline & $\begin{array}{c}\text { Completely } \\
\text { confident - }\end{array}$ & $\begin{array}{c}\text { Not confident } \\
\text { at all }\end{array}$ & $\begin{array}{c}\text { Somewhat } \\
\text { confident - }\end{array}$ \\
\hline $\begin{array}{c}\text { Confidence in } \\
\text { preparedness for } \\
\text { disaster (Q8) }\end{array}$ & $66(44 \%)$ & $4(3 \%)$ & $79(53 \%)$ \\
\hline $\begin{array}{c}\text { Awareness of EOP } \\
(Q 9)\end{array}$ & $71(48 \%)$ & $2(1 \%)$ & $76(51 \%)$ \\
\hline
\end{tabular}

Table 1: Confidence in EOP awareness and preparedness.

The researcher also sought to determine whether the nurses could adequately describe the EOP terms. Only $21 \%(n=35)$ of the ED nurses provided the correct definition of the terms. The findings presented in Table 2 show a statistically significant association when the confidence in preparedness for disaster when gender was considered $(\mathrm{p}<0.05)$. The female nurse population in the ED is clearly larger than the male nurse cadres but has the exact same scope of practice. Thus, the findings showed that the female nurses' 
preparedness confidence level is lower than the male nurses $(40 \%$, $\mathrm{n}=56$ ). In contrast, male nurses' preparedness confidence level is high $(55 \%, \mathrm{n}=10)$.

\begin{tabular}{|l|c|c|c|c|c|}
\hline & $\begin{array}{c}\text { Com- } \\
\text { pletely } \\
\text { confident }\end{array}$ & $\begin{array}{c}\text { Somewhat } \\
\text { confident }\end{array}$ & $\begin{array}{c}\text { Not } \\
\text { confident } \\
\text { at all }\end{array}$ & $\begin{array}{c}\text { p-value } \\
\text { (Pearson } \\
\text { correla- } \\
\text { tion) }\end{array}$ \\
\hline Male & 10 & 9 & 0 & 19 & 0.000 \\
\hline Female & 56 & 70 & 4 & 141 & \\
\hline Total & 66 & 79 & 4 & 163 & \\
\hline
\end{tabular}

Table 2: Cross-tabulation of preparedness for disaster and gender.

The all participated ED nurses were also asked to describe their understanding of EOP. As the findings show, fewer ED nurses reported that they could adequately describe EOP $(21 \%, n=35,1$ Head nurse, 6 Charge nurses, 8 SN1, 20 SN2).

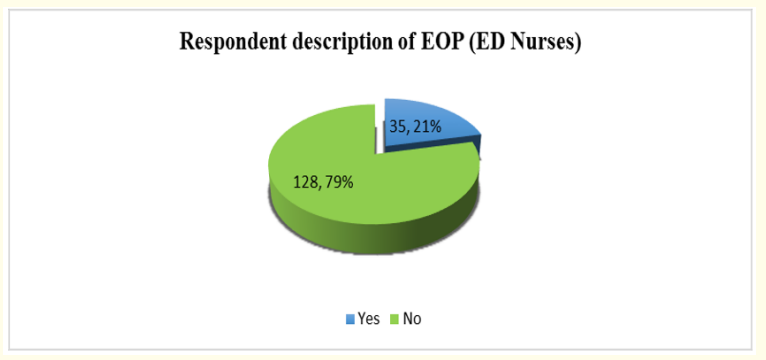

Figure 5: Respondent's ability to describe EOP (ED Nurses).

The largest proportion $(33.2 \%, \mathrm{n}=43)$ of ED nurses who answered question 17 included all types (Head nurse, charge nurse, SN1, SN2, and SN3) were not confident enough to activate the EOP if there was an emergency at hand. Thirty six percent (36\%) of the respondents were uncertain on how they would activate the EOP whenever there was an emergency (See Table 3).

\begin{tabular}{|c|c|c|}
\hline Confidence in activating EOP & Frequency & Percent \\
\hline I cannot answer this question & 47 & $36.4 \%$ \\
\hline No, I am not & 43 & $33.3 \%$ \\
\hline Yes, I am & 39 & $30.2 \%$ \\
\hline Total & 129 & $100.0 \%$ \\
\hline
\end{tabular}

Table 3: Respondent's confidence in EOP Activation.
Despite the low confidence in EOP activation highlighted in table 3, approximately $80.62 \%(n=104)$ of 129 respondents were interested in learning about the EOP. However, $19.38 \%(n=25)$ responded that they were not interested in learning about the EOP activation (See Table 4).

\begin{tabular}{|c|c|c|}
\hline $\begin{array}{c}\text { Willingness to learn about EOP } \\
\text { activation }\end{array}$ & Frequency & Percent \\
\hline No, I am not & 25 & $19.38 \%$ \\
\hline Yes, I am & 104 & $80.62 \%$ \\
\hline Total & 129 & $100.0 \%$ \\
\hline
\end{tabular}

Table 4: Willingness of respondents to learn about EOP.

In terms of persons responsible for communicating EOC whenever there was an emergency, most respondents indicated that it was the ED Head nurse's (Senior and administrative nurse) responsibility ( $\mathrm{n}=41)$. Even though some respondents noted that everyone in the department they worked for could take up the responsibility, others mentioned the Charge nurse (Practitioner and team leader and deputy supervisor) as responsible (See Figure 6).

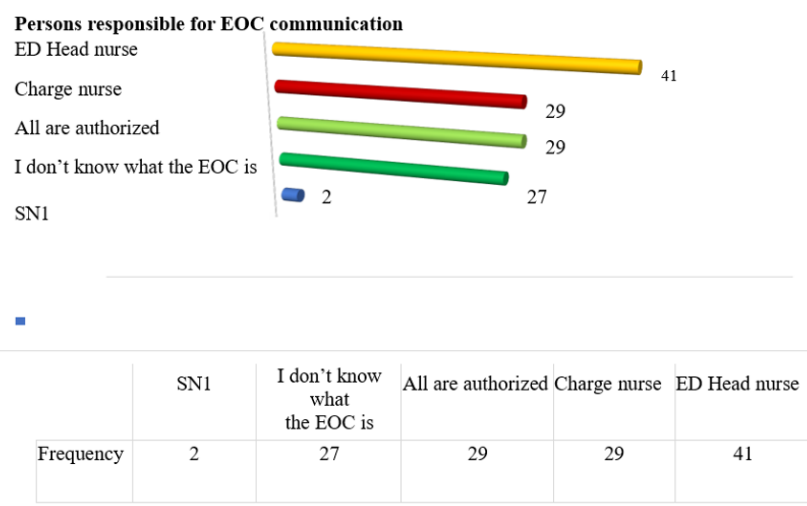

Figure 6: Persons responsible for EOC communication.

This study also evaluated the respondent's confidence in how appropriately they would fill out EOC forms should a disaster occur. Of 128 nurses who responded to the inquiry, 13\% nurses (n= 16; 1 head nurse, 2 charge nurses, 6 SN1, 7 SN2) were completely confident. In contrast, $46 \%(n=59)$ were not confident at all. Fortyone percent $(n=53)$ indicated that they were somewhat confident (See Table 5). 


\begin{tabular}{|c|c|c|}
\hline & Frequency & Percent \\
\hline Completely confident & 16 & $13 \%$ \\
\hline Not confident at all & 59 & $46 \%$ \\
\hline Somewhat confident & 53 & $41 \%$ \\
\hline Total & 128 & $100 \%$ \\
\hline
\end{tabular}

Table 5: Confidence of ED Nurses in filling EOP forms.

A cross-tabulation between gender and the confidence of nurses to fill EOP forms was also conducted. The confidence of the respondent filling the EOP forms did not differ by gender, ${ }^{2}(2, \mathrm{n}=$ 128) $=2.6431, p=$ n.s. Therefore, there is no significant association between gender and the respondents' confidence in filling EOP forms (See Table 6).

\begin{tabular}{|c|c|c|c|c|c|}
\hline & $\begin{array}{c}\text { Com- } \\
\text { pletely } \\
\text { confident }\end{array}$ & $\begin{array}{c}\text { Some- } \\
\text { what } \\
\text { confident }\end{array}$ & $\begin{array}{c}\text { Not con- } \\
\text { fident at } \\
\text { all }\end{array}$ & $\begin{array}{c}\text { p-value } \\
\text { (Pearson } \\
\text { correlation) }\end{array}$ \\
\hline Male & 4 & 6 & 6 & 16 & 0.266 \\
\cline { 2 - 6 } & 12 & 47 & 53 & 112 & \\
\hline Female & 16 & 53 & 59 & 128 & \\
\hline Total & 16 & & & & \\
\hline
\end{tabular}

Table 6: Correlation of gender vs. filling EOP forms.

Theme 3: Disaster educational programs and practical opportunities

Nearly half of the nurses $(46.6 \%, n=52)$ noted that they had had a practice opportunity to input disaster codes in the EOC. However, $31.3 \%(n=40)$ had never had the opportunity. The Remaining $28.1 \%$ had no idea what EOC was. See figure 7.

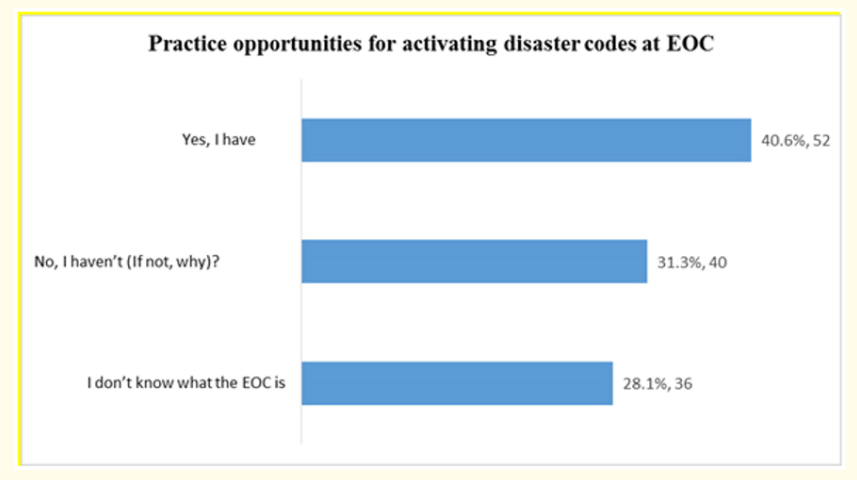

Figure 7: Practice opportunities for activating disaster codes at EOC.
There was no significant association between employee cadres and the respondents' ability to activate EOP in the case of disaster, $x^{2}(4, n=128)=1.425, p>0.05$. Therefore, this means that the respondents didn't have enough opportunity to operationalize EOP tools by the positions they held in the organization.

\begin{tabular}{|c|c|c|c|c|c|}
\hline Designation & Yes & No & Total & $\begin{array}{c}\text { Chi-Square } \\
\text { statistic }\end{array}$ & $\begin{array}{c}\text { p- } \\
\text { value }\end{array}$ \\
\hline Charge nurse & 3 & 3 & 6 & \multirow{6}{*}{1.425} & \multirow{6}{*}{0.840} \\
\hline ER Head nurse & 2 & 24 & 26 & & \\
\hline SN1 & 17 & 48 & 65 & & \\
\hline SN2 & 29 & 1 & 30 & & \\
\hline SN4 & 1 & 0 & 1 & & \\
\hline Total & 52 & 76 & 128 & & \\
\hline
\end{tabular}

Table 7: Association between the respondents' cadre and EOP activation.

In terms of ED nurses' awareness of TTX activities, 52 (40.63\%) indicated that they were aware, but $59.38 \%(n=76)$ were not (See Table 8). Further, only $16.50 \%$ ( $n=21 ; 2$ head nurses, 6 SN1, 13 SN2) noted that they understood what HICS meant. Regarding the respondents' confidence to evacuate victims or patients as per the EOP procedures during the disaster, a high percentage (56.69\%) of nurses were confident in affirming their ability in such set-ups and, in contrast, remained nurses were unconfident as $43.31 \%(n=56)$.

\begin{tabular}{|c|c|c|}
\hline $\begin{array}{c}\text { As an ED nurse, do you know what a } \\
\text { TTX exercise is? }\end{array}$ & $\begin{array}{c}52 \\
(40.63 \%)\end{array}$ & $\begin{array}{c}76 \\
(59.38 \%)\end{array}$ \\
\hline $\begin{array}{c}\text { If so, have you ever been engaged/par- } \\
\text { ticipated in the TTX } \\
\text { exercise at MDRU? }\end{array}$ & $\begin{array}{c}23 \\
(18.11 \%)\end{array}$ & $\begin{array}{c}104 \\
(81.89 \%)\end{array}$ \\
\hline $\begin{array}{c}\text { As an ED nurse, do you know what the } \\
\text { term HICS means? }\end{array}$ & 21 & $\begin{array}{c}107 \\
(16.50 \%)\end{array}$ \\
\hline $\begin{array}{c}\text { Are you confident in your ability to } \\
\text { evacuate victims/patients as the EOP } \\
\text { procedures set during the disaster? }\end{array}$ & $\begin{array}{c}72 \\
(56.69 \%)\end{array}$ & $\begin{array}{c}56 \\
(43.31 \%)\end{array}$ \\
\hline
\end{tabular}

Table 8: Application of TTX, Training uptake, and EOP procedures application.

Theme 4: Resources of risk assessment (THIRA and HVA)

The findings indicate that there was minimal capacity in the utilization of risk assessment tools. Only 46 (35\%) respondents indi- 
cated that they had been taught about the tools, yet an overwhelming $65 \%(n=84)$ had not.

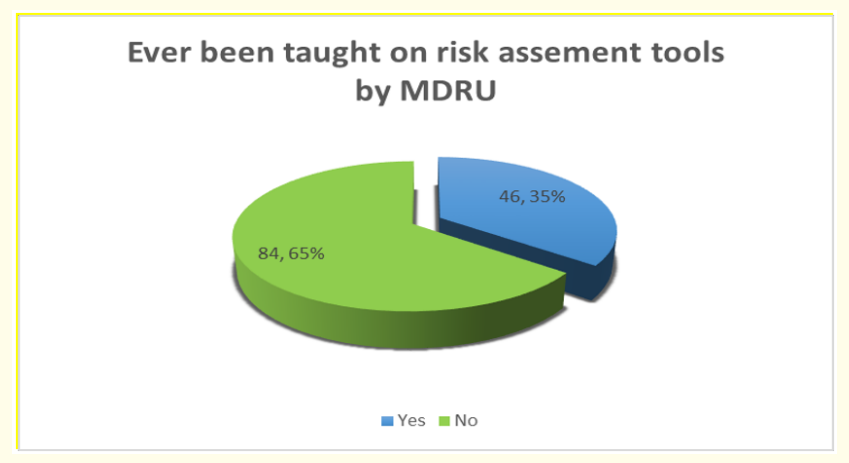

Figure 8: Training on risk assessment tools.

The respondents' awareness of risk assessment tools was low $(33.33 \%, n=43)$ (See Figure 10). The remaining 67\% $(n=86)$ either did not know what EOP is, were not aware of any risk assessment tools, and some of participants indicated that they did not want to answer the question.

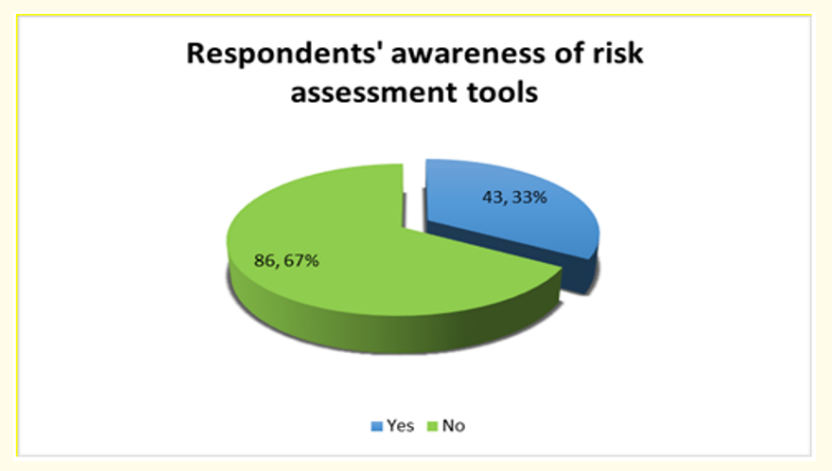

Figure 9: Awareness of risk assessment tools.

Some of the emergency scenarios that the respondents thought could happen in hospitals include fires, bombs, earthquakes, chemical spills, abduction, accidents, and wars, among others, as seen in table 9.

Furthermore, the study recommendations were derived from the respondents' attitudes towards suggestions supplied by the researcher. The results presented show that many respondents support the idea that educational programs were necessary to en-

\begin{tabular}{|c|c|}
\hline Likely calamities in hospitals & Frequency \\
\hline Fire & 89 \\
Bomb & 74 \\
Earthquakes & 29 \\
Chemical spill & 25 \\
Abduction & 13 \\
Accidents & 13 \\
War & 13 \\
External disaster & 10 \\
Internal disaster & 10 \\
Trauma & 9 \\
\hline Major Disaster & \\
\hline Covid outbreak & 7 \\
Food poison & 6 \\
Natural Disaster & 6 \\
Building collapse & 5 \\
Gas leak & 5 \\
Mass casualties & 5 \\
System failure & 4 \\
Biological weapons & 3 \\
Medivac & 3 \\
Weather changes & 3 \\
Nuclear & 2 \\
Code Amber & 1 \\
\hline
\end{tabular}

Table 9: Respondents' views on calamities likely to happen in hospitals.

hance an individual's competence in case of any disaster. Based on this, education should be conducted annually as per the suggestions by $115(91 \%)$ respondents. See figure 10.

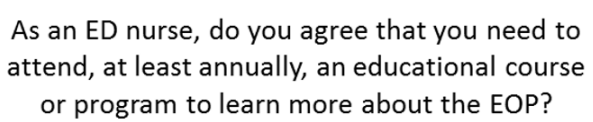

or program to learn more about the EOP?

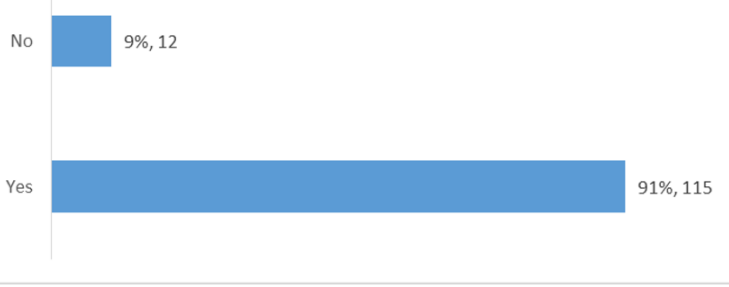

Figure 10: Perception on the use of education to enhance disaster response competence. 
Apart from rolling out such educational programs, $(89 \%, \mathrm{n}=$ 113) of the respondents require constant training on the risk assessment tools. Often, there are changing needs depending on the type of disasters that people experience. See figure 11.

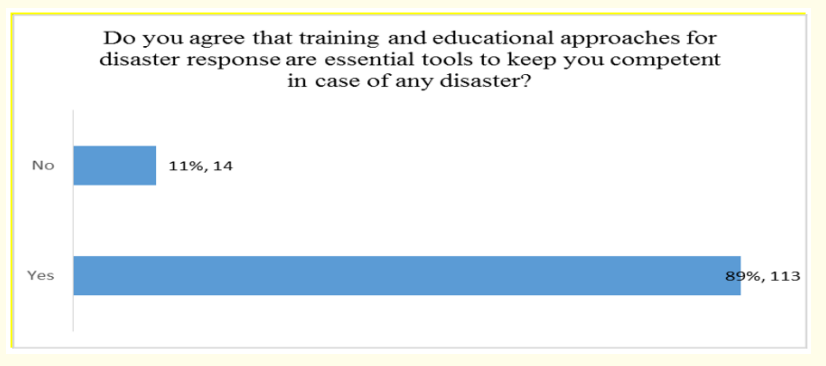

Figure 11: Frequency of EOP Educational courses.

\section{Discussion}

The study's primary objective was to evaluate the level of awareness of the EOP and preparedness among emergency department nurses for a large-scale disaster that they would be involved in its response. Three themes formed the primary basis for developing a conclusive determination of whether such respondents were aware and prepared. The respondents evaluated in the study were overwhelmingly female, with over $88 \%$ representation compared to the male counterparts. The value of information and consistency was established from the idea that most respondents had spent a significantly long time working for the organization. Nearly threequarters of the respondents indicated that they had worked for more than two years in their respective posts. However, half of the respondents had been in the organization for more than four years.

The level of confidence of awareness and preparedness for disaster management was first among the themes that the study evaluated. A majority of the ED nurses exuded little confidence in how they believed they could handle disasters. The Emergency Operation Plan (EOP) provides guidelines through which medical practitioners and nurses, in particular, can utilize in preparing and implementing emergency operations. The study found that very few nurses were aware of some EOP's terms and operations, and some are not confident of those terms and how to operate and respond in a disaster. Likewise, ED nurses are in desperate need to acquire many opportunities to cultrate the importance of being aware of EOP, which leads to equipping competent ED nurses to confront any sudden disaster. Because of this, more than half of them expressed a lack of confidence in the EOP awareness and preparedness in disaster management. Considering that the nurses are baseline responders in any calamity, their confidence to provide services should be higher than reported. This boosts the public confidence in their rescuers as well.

Secondly, the researcher investigated whether the nurses have been taken through practical drills and educational modules for disaster management. This was considerably lacking as many people did not understand what EOP was, and a large proportion had not been offered the opportunity to partake in disaster management drills. The ED nurses expressed relatively divergent views in understanding EOP as in both groups, very few could understand it. In terms of access to resources of risk management, several concerns were noticeable. Nearly 35\% ( $=83$ ) of participating ED nurses had not received any education from the Major Disaster Response Unit (MDRU) on implementing the risk assessment tools. This was further constrained by the fact that the respondents were not even aware of such tools.

\section{Study limitations}

There was non-response bias introduced by respondents who did not fill the questions. Such errors lower the sampling saturation and, as such, dilutes the statistical assumptions made on the constructs. Nonetheless, the conclusions were made based on those respondents who responded to the respective constructs of interest. Besides, a very few participants couldn't answer some questions for some reasons, such as a technical issue that did not majorly affect the data.

Moreover, there was limited time in executing proper data collection procedures. Also, there were limited interactions from the hospital due to COVID-19 restrictions. This limited the opportunities for observing and physically documenting information that required the researchers' perspective.

\section{Conclusions and Recommendations}

Training should build upon gaps in the nurses' familiarity with the EOP, specifically their perception of their roles and preparedness for practical implementation. Educational programs should detail the principles of mitigation, preparedness, response, and recovery to ensure that they account for the changing landscape of 
hazards, threats, and regulatory requirements. Sultan., et al. 2020

[14] concur that complying with the standards of the emergency management educational programs would ensure that ED nurses improve response and recovery from disasters. As such, the EOP should detail specific plans, command center activities, and incident implementation to enhance the nurses' perception, increase the level of preparedness, and allow for the practical implementation of an all-hazards plan. Disaster education and training through the educational programs may help create and bolster the foundation for existing programs while allowing for a cohesive and effective response to disasters.

Additionally, a report will be prepared with proposed educational program to be delivered to the director of nursing services at PSMMC for the authorization of further training of nurses in areas where gaps have been identified. The report will present outcomes and identify the key areas of concern with nurses' familiarity with the EOP. The Three Ps program is designed to train nurses while focusing on the gaps outlined in the research outcomes.

The Three Ps program will be developed and delivered to ED nursing staff to enhance their disaster preparedness. The Three Ps program includes Perception, Preparedness, and Practical implementation. Under the perception phase, the knowledge of staff will be enhanced through educating nurses on the existing EOP and relevant disaster preparedness requirements. This is the theoretical phase which seeks to enhance staff perceptions of disaster preparedness and improve their knowledge on the relevant concepts [27]. Therefore, this initial phase will be conducted using a PowerPoint presentation targeting ED nurses. The presentation will be delivered as an independent course at www.psmmc.med.sa/mdru.

The second phase of preparedness will be practical preparation for disaster and will include seminars and table-top exercises (TTX) for the ED nurses. TTX are essential in simulating a disaster scenario and advantageous in that they can be manipulated to fit the training requirements for nurses. This phase will be delivered as Zoom sessions (four sessions annually). The nurses who completed the independent course can register to attend the seminars and TTX session. After the preparedness phase, ED nurses will be exposed to the practical phase that is in the Emergency Operations Center (EOC) to learn how responses are carried out. The rotation schedules will be harmonized by the MDRU staff and send the avail- able seats for EOC rotation to the ED nurse's head nurse. This last phase could also be implemented in a real disaster incident where nurses are brought to the frontline of disaster response to put in practice their preparedness training (See appendix C).

Moreover, enrolling ED nurses in introductory disaster training courses will equip them to respond to disasters. The Mississippi State Department of Health, 2017 [28] approves basic training to equip each nurse to individualize nursing interventions in planning for and managing disasters. For example, Basic Disaster Life Support would improve the awareness and competencies of ED nurses by equipping them to address injuries from public health disasters. Next, IS-100 (Introduction to the Incident Command System) would introduce the nurses to the incident command system (ICS). IS-200 (Basic Incident Command System for initial Response) would prepare the nurses to take on supervisory positions within the ICS. Similarly, IS-242 (Effective Communication) would expose ED nurses to proven effective communication skills to equip them for developing action plans. With Naser and Saleem, 2018 [29] who asserting the readiness of nurses to learn about disaster management, these short courses would ensure they operate efficiently during disasters. The standardized introductory courses, which extend to IS-700 (Introduction to the National Incident Management System) and IS-800 (Introduction to the National Response Framework), would expose ED nurses to the national incident management system and build their knowledge of national response frameworks to ensure that multi-agency coordination supports a national response. Most assuredly, these fundamental courses are essential guides for enhancing the education efforts in disaster preparedness.

Internal and external conferences are suitable for sharing lessons learned from emergency preparedness. The conferences are planned and executed jointly with academic institutions, emergency organizations, civilian entities, managers, and practitioners from various professions. Adini., et al. 2016 [30] assert that conferences allow for sharing insights from diverse disasters and emergencies to substantiate the knowledge and experiences of professionals participating in the proceedings. These conferences also promote international networking opportunities between parties while providing unique opportunities for improving emergency preparedness. The Prince Sultan Military Medical City emergency department may use conferences as a platform for exchanging ex- 
periences from internal and external researchers and practitioners involved in emergency preparedness and disaster response. The involvement of internal and external experts with vast experience in conferences may maximize nurses' exposure to diverse aspects of emergencies and disasters. More often, training on responsibilities and role knowledge target senior leaders that manage command centers during disaster response. In these incidences, relying on the expertise and instruction of the incident command center only causes a delay in the immediate response efforts by staff. Therefore, improving the nurse's perception of preparedness by educating them on their roles and responsibilities during the chaotic time may streamline their efforts with the most.

Current hospital's EOPs and response plans. Rizqillah and Suna, 2018 [31] support the recommendation that since ED is the entry point into healthcare systems during disasters, ED nurses should be knowledgeable in accessing and using EOPs and plans during disaster response to ensure congruency with the healthcare delivery system during high-stress events. These findings reaffirm the need to improve the perceptions of preparedness by exposing ED nurses to the current hospital's EOPs and plans.

Considering the ever-increasing natural and man- made disasters, there is a need to equip nurses and first-line response on the requisite tools for disaster management. Some of the nurses' underlying challenges indicated a lack of awareness of relevant tools to guide disaster response. This necessitates the governmental, privet, and other stakeholders to educate the relevant parties on EOP and its operationalization.

The importance of disaster preparedness is essential in the preservation of life. According to Venkatesan., et al. 2021 [32], the comprehension of disaster management remains a great concern currently considering the influx of the COVID 19 pandemic. The US has been at the forefront, providing a solution to avert unnecessary deaths. However, the onset of the pandemic exposed the vulnerabilities of the healthcare system to handle a disease of such proportions. Al-Zahrani., et al. 2021 [33] also expressed their reservations about Saudi Arabia's capacity to handle a pandemic. Therefore, this study concludes that there is a limited capacity in the country's ability to handle the current any disaster in the future. Consequently, the need to educate ED nurses and first-line responders cannot be ignored. This will help equip and prepare them to handle future disasters better.

\section{Bibliography}

1. Madrigano J., et al. "Beyond disaster preparedness: building a resilience-oriented workforce for the future". International Journal of Environmental Research and Public Health 14.12 (2017): 1563.

2. Alzahrani $\mathrm{F}$ and Kyratsis Y. "Emergency nurse disaster preparedness during mass gatherings: A cross-sectional survey of emergency nurses' perceptions in hospitals in Mecca, Saudi Arabia". BMJ Open 7.4 (2017).

3. Al-Bassam A M., et al. "Natural hazards in Saudi Arabia. In Extreme natural events, disaster risks and societal implications" (2014): 243-251.

4. World Health Organization definitions: emergencies.

5. Preston J., et al. "Community response in disasters: An ecological learning framework". International Journal of Lifelong Education 34.6 (2015): 727-753.

6. Drabek T E. “The human side of disaster". CRC Press (2016).

7. Saudi Gazette. "Single-day deaths drop to record low as KSA sees steady fall in COVID-19 cases" (2021).

8. Shalhoub A A B., et al. "Evaluation of disaster preparedness for mass casualty incidents in private hospitals in Central Saudi Arabia”. Saudi Medical Journal 38.3 (2017): 302.

9. Nofal A., et al. "Knowledge, attitudes, and practices of emergency department staff towards disaster and emergency preparedness at tertiary health care hospital in central Saudi Arabia”. Saudi Medical Journal 39.11 (2018): 1123.

10. VanDevanter N., et al. "Challenges and resources for nurses participating in a Hurricane Sandy hospital evacuation". Journal of Nursing Scholarship 49.6 (2017): 635-643.

11. Azmani S., et al. "Challenges of communication system during emergency disaster response in Malaysia: A review". Journal of Fundamental and Applied Sciences 9.4S (2017): 890-904.

12. Roud E. "Collective improvisation in emergency response". Safety Science 135 (2021): 105104.

13. AlShowair A., et al. "Review of hospital disaster preparedness in Arabian Gulf countries". ACTA Medical Sciences 3.9 (2019): 86-94. 
14. Sultan M A S., et al. "Nurses' readiness for emergencies and public health challenges-The case of Saudi Arabia". Sustainability 12.19 (2020): 7874 .

15. Repoussis PP., et al. "Optimizing emergency preparedness and resource utilization in mass-casualty incidents". European Journal of Operational Research 255.2 (2016): 531-544.

16. Yip S H F. "A mixed-integer linear programming model for disaster housing supply chain design and optimization (Doctoral dissertation, Massachusetts Institute of Technology)” (2019).

17. Farcas A., et al. "Use of incident command system for disaster preparedness: A model for an emergency department COVID-19 response". Disaster Medicine and Public Health Preparedness (2020): 1-6.

18. Rahmati-Najarkolaei F., et al. "Assessment of a military hospital's disaster preparedness using a health incident command system". Trauma Monthly 22.2 (2017).

19. California Hospital association. "Hospital incident command system (HICS)" (2017).

20. Al Thobaity A., et al. "Exploring the necessary disaster plan components in Saudi Arabian hospitals". International Journal of Disaster Risk Reduction 41 (2019): 101316.

21. Khankeh H., et al. "Developing accreditation standards for disaster risk management: An approach for hospital preparedness improvement-editorial". Journal of Military Medicine 20.6 (2018): 574-576.

22. CBAHI. Essential national requirements for patient safety (2019).

23. Al Thobaity A., et al. "Exploring the necessary disaster plan components in Saudi Arabian hospitals". International Journal of Disaster Risk Reduction 41 (2019): 101316.

24. Bajow N A and Alkhalil S M. "Evaluation and analysis of hospital disaster preparedness in Jeddah". Health 6.19 (2014): 2668.

25. Joint Commission International (n.d.). $6^{\text {th }}$ edition in-depth: Structural integrity of patient care environments in the event of a disaster (2019).

26. Nassaji H. "Qualitative and descriptive research: Data type versus data analysis". Language Teaching Research 19.2 (2015): 129-132.
27. Barbosa F. "Emergency health care system and its role in national disasters". Journal of Humanities Insights 2.1 (2018): 14-20.

28. Mississippi State Department of Health. Emergency Planning and Response Training Catalog (2017).

29. Naser W N and Saleem H B. "Emergency and disaster management training; knowledge and attitude of yemeni health professionals- a cross-sectional study". BMC Emergency Medicine 18.1 (2018).

30. Adini B., et al. "Learning lessons in emergency management: The $4^{\text {th }}$ International Conference on healthcare system preparedness and response to emergencies and disasters". Disaster and Military Medicine 2.1 (2016): 1-6.

31. Rizqillah A F and Suna J. "Indonesian emergency nurses' preparedness to respond to disaster: A descriptive survey". Australasian Emergency Care 21.2 (2018): 64-68.

32. Venkatesan C., et al. "Rapid Operationalization of a Large-Scale Covid-19 Vaccination Program in an Integrated Community Health System". NEJM Catalyst Innovations in Care Delivery 2.1 (2021).

33. Al-Zahrani M A., et al. "Impact of COVID-19 on Urology Practice in Saudi Arabia". Risk Management and Healthcare Policy 14 (2021): 1379.

\section{Assets from publication with us}

- Prompt Acknowledgement after receiving the article

- Thorough Double blinded peer review

- Rapid Publication

- Issue of Publication Certificate

- High visibility of your Published work

Website: www.actascientific.com/

Submit Article: www.actascientific.com/submission.php

Email us: editor@actascientific.com

Contact us: +919182824667 